Int. J. Plant Sci. 162(3):607-616. 2001.

(C) 2001 by The University of Chicago. All rights reserved.

$1058-5893 / 2001 / 16203-0012 \$ 03.00$

\title{
TRANSLATIONAL AND FLUCTUATING ASYMMETRY AS TOOLS TO DETECT STRESS IN STRESS-ADAPTED AND NONADAPTED PLANTS
}

\author{
C. L. Alados, ${ }^{1, *}$ T. Navarro, ${ }^{2, \dagger}$ J. Escós, ${ }^{*}$ B. Cabezudo,† and J. M. Emlen ${ }^{3,} \ddagger$ \\ *Instituto Pirenaico de Ecología (CSIC), Avenida Montañana 177, Apartmento 202, 50080 Zaragoza, Spain; †Departmento de Biología \\ Vegetal, Universidad de Málaga, Apartmento 59, 29080 Málaga, Spain; and ¥Biological Resources Division, U.S. Geological \\ Survey, 6505 NE 65th Street, Seattle, Washington 98115-5016, U.S.A.
}

\begin{abstract}
Plants having experienced previous exposure to a stress are expected to be more resistant to further stress than those not having been exposed. While the assessment of stress in plants is a difficult task, particularly for stress-adapted plants, developmental instability has proven a useful tool for assessing stress in organisms. We examined the effect of water availability on developmental instability (translational asymmetry and fluctuating asymmetry) and growth of Anthyllis cytisoides L. under a precipitation gradient. We compared A. cytisoides in very xeric (Almería, $256 \mathrm{~mm}$ of average rainfall) and subhumid (Málaga, $613 \mathrm{~mm}$ of average rainfall) areas, from north- and south-facing slopes, after both a period of extreme drought (1995) and a humid period (1997). Translational symmetry varied between north- and south-exposed plants but differently for the Almería and Málaga populations. We observed that developmental stability was enhanced in southexposed plants in the population from the more xeric habitat (Almería) after both dry and humid periods. In contrast, A. cytisoides living in a subhumid habitat did not alter their developmental stability in response to exposure after a humid period but exhibited a decline in stability in south-exposed slopes after a dry period. That is interpreted as a consequence of the adaptation of A. cytisoides to aridity. Growth patterns were also investigated. By reducing growth, plants can mitigate stress through a reduction of water and nutrient demands, allowing the maintenance of a steady supply of nutrients for developmental stability. This strategy was followed by plants acclimated to drought. But in mild weather, such as that of Montes de Málaga, a high growth rate cannot be supported when water is scarce. We also observed that floral fluctuating asymmetry was greatest on north-facing slopes at both the Almería and Málaga sites. That is, southern exposure enhanced floral homeostasis during development. Additionally, comparisons between translational and fluctuating asymmetry showed that translational asymmetry is more sensitive to environmental change than fluctuating asymmetry.
\end{abstract}

Keywords: developmental instability, translational asymmetry, fluctuating asymmetry, water deficit, Anthyllis cytisoides L.

\section{Introduction}

Previous studies have demonstrated that the disruption of homeostasis during development (developmental instability) can be used to detect stress in organisms (Soule 1987; Zakharov 1987; Parsons 1990). Developmental instability is the degree of developmental error (intraindividual variability in an otherwise nonvariable set of traits) induced by environmental disturbances (Graham et al. 1993). Traditionally, it has been assessed by measuring fluctuating asymmetry, random deviations from bilateral symmetry (Ludwig 1932; Van Valen 1962; Palmer and Strobeck 1986). Levels of fluctuating asymmetry have been shown to be related to environmental conditions (Parsons 1990; Alados et al. 1993; Clarke 1993; Freeman et al. 1993, 1999; Graham et al. 1993; Møller and Swaddle 1997) and individual quality (Møller and Pomiankowski 1993; Watson and Thornhill 1994; Markow 1995;

${ }^{1}$ E-mail alados@ipe.csic.es.

${ }^{2}$ E-mail tnavarro@uma.es.

${ }^{3}$ E-mail John_Emlen@usgs.gov.

Manuscript received April 2000; revised manuscript received November 2000.
Møller and Thornhill 1998). Because their modular nature presents repeated structures developed under the same pathway, plants are good subjects for estimating the capacity of the genotype to control developmental error. Most studies on plant developmental instability have utilized fluctuating asymmetry of leaves and flowers (see Møller and Shykoff 1999 for review). In addition to bilateral asymmetry, statistical noise in other allometric relations can also be used to detect random intraindividual variability during development (Freeman et al. 1993; Graham et al. 1993; Alados et al. 1994, 1998a, 1998b, 1999; Escós et al. 1995, 1997, 2000; Sherry and Lord 1996; Anne et al. 1998). Additionally, and because previous studies have revealed that vegetative and reproductive structures might vary differently in response to environmental conditions (Alados et al. 1998b), we performed developmental instability analyses on both vegetative and reproductive structures.

Plant physiological and evolutionary responses to water stress depend on the range of resource availabilities to which the plants are adapted (Chapin 1988). Plants having experienced previous exposure to a stress are expected to be more able to resist further stress than organisms that previously have not faced such situations. Plants facing frequent drought pe- 
riods evolve a conservative strategy that consists of the ability to reduce growth under severe drought (Grime 1979; Chapin 1980, 1991; Levitt 1980) while still maintaining homeostasis of fundamental structures for fitness. In contrast, plants living in more mesic habitats may present a more competitive strategy (Bertness and Callaway 1994), allocating more energy to production, while still being able to maintain developmental stability (homeostasis) in growth structures, except in the face of occasional drought periods.

In this study, we analyze trends in developmental stability and growth rhythm of Anthyllis cytisoides L. under different water-deficit conditions. Anthyllis cytisoides is intimately associated with grazing regimens, being a preferred food species for domestic animals (Barroso 1991). Past studies on the effect of grazing on A. cytisoides showed that intermediate grazing pressure favors both adult survival and homeostatic maintenance of morphological allometries (Alados et al. 1994; Escós et al. 1997, 2000). Varying slope and aspect provide a variation in solar energy and its effects on evapotranspiration that control the soil moisture regimen (Ayyad and Dix 1964; Coxson and Looney 1986; Nevo 1997, 1998), providing a gradient to study plant tolerance to water deficit. We used plants living on north- and south-facing slopes from two populations, which differ in average rainfall $(256 \mathrm{~mm}$ in Almería, $613 \mathrm{~mm}$ in Málaga) after both a dry (1995) and a humid period (1997). This experiment permitted us to investigate adaptive plant responses to environmental change. We can use the relation between growth and developmental stability to explore strategic responses to environmental stress and to determine whether stress resistance mechanisms have evolved.

\section{Material and Methods}

\section{Study Area}

We selected two areas ca. $250 \mathrm{~km}$ apart. One was the Rambla Honda Valley, located near Tabernas in Los Filabres Range (Almería, Spain), lat. $37^{\circ} 08^{\prime} \mathrm{N}$, long. $2^{\circ} 22^{\prime} \mathrm{W}$, and 600-900 m altitude. The climate is semiarid; annual mean temperature is $15.8^{\circ} \mathrm{C}$ and annual mean rainfall is $256 \mathrm{~mm}$ (Puigdefábregas et al. 1996). Rainfall in the spring of 1995 was $14.5 \mathrm{~mm}$, i.e., $21 \%$ of average spring rainfall (R. Lázaro, personal communication). During 1996, rainfall increased to $333.29 \mathrm{~mm}$, $104.72 \mathrm{~mm}$ falling in the spring of 1997.

The other study area was located in the Montes de Málaga Mountain Range (Málaga, Spain), lat. $36^{\circ} 47^{\prime} \mathrm{N}$, long. $4^{\circ} 33^{\prime} \mathrm{W}$, and $200-850 \mathrm{~m}$ altitude. The climate is subhumid. Annual mean temperature is $15.6^{\circ} \mathrm{C}$ and annual mean rainfall is 613 $\mathrm{mm}$. During 1995, rainfall was $64 \%$ of average, and most precipitation $(203 \mathrm{~mm}$ ) fell in December. During the spring of 1995 , there was only $48.2 \mathrm{~mm}$ of rainfall. In 1996, rainfall was $1179.2 \mathrm{~mm}$, while in the spring of 1997 (March, April, and May), there was $106.2 \mathrm{~mm}$ of rainfall.

The natural vegetation at Rambla Honda (Almería) includes shrubs and thorny shrubs, with monospecific patches of $A n$ thyllis cytisoides and Stipa tenacissima L. grass. Artemisia barrelieri Besser is scattered throughout the area. The vegetation at Montes de Málaga is a shrub land of Genista umbellata (L'Hér.) Poiret and A. cytisoides.

Anthyllis cytisoides (Leguminoseae) is a western Mediter- ranean, endemic leguminous species that lives in nearly monospecific patches. It is a winter-deciduous shrub, $50-125 \mathrm{~cm}$ high, much branched with an apical inflorescence. The inflorescence is a simple spikelike raceme of fasciculated (two to three) flowers in the axils of bracts. The corolla is zygomorphic, Papillonaceae type, and yellow. Flowers are mellitophylus, sternotribic (chest rubbing), and bee pollinated (Arroyo 1981). Previous experiments consisting of isolating plants from pollination by transparent net bags yielded no seeds, demonstrating that A. cytisoides has obligate insect pollination. We have studied the vexilla and alaes, which are essential floral pieces of the pollination mechanism.

\section{Data Collection and Analyses}

We performed a $2 \times 2$ factorial design, comparing the effect of slope exposure on the plant morphological response of two populations with different levels of water deficit: Almería (xeric) and Málaga (subhumid). Later, we compared observations after a dry period (1995) and after a humid period (1997). Differences between slope exposures were due only to sun irradiance and its related effects on water evaporation and enhanced UV-B radiation. Nitrogen is the major nutrient limiting productivity in most terrestrial habitats (Tilman and Dowing 1994). Because A. cytisoides is a symbiotic N-fixing legume, it is not dependent on soil nitrogen availability. Additionally, symbiotic nitrogen fixation is very sensitive to water deficit (Sprent 1972; Gallacher and Sprent 1978). Thus, despite possible soil characteristic difference at the Málaga and Almería study sites, we assume that water deficit is the most important factor affecting performance of this leguminous plant.

We selected 40 A. cytisoides plants per treatment in two parallel transects (20 per transect), with a total of 320 plants collected for this experiment. The two areas were ungrazed. We chose adult plants of similar size in order to reduce variability in the analysis. Each plant was divided into three parts with respect to height. From each individual plant, we selected from the middle strata one 3-yr-old branch. Additionally, we selected a well-developed annual shoot from each branch.

Plant growth was estimated as the total length of a welldeveloped annual shoot. Floral asymmetries and internode lengths were all examined to detect consistency in developmental stability.

Fluctuating asymmetry. The asymmetry of flowers was examined by measuring the width on each side of the midaxis at the midpoint of the vexillum at the level of the maximum width, and by measuring the largest width of each alae (fig. 1). Floral asymmetry was measured only in plants collected in 1997. We selected 15 plants per transect and two flowers per plant, making a total of 352 flowers analyzed, 118 from Málaga and 234 from Almería. Each flower was measured two times in order to calculate measurement error. Measurements were taken with a Visilog5.1 from Noesis image processing over a SPARC STATION 20 sun and with a camera CCD $\mathrm{B} / \mathrm{N}$ (Sony) with macro objective. The image obtained is $512 \times 512$ pixels with 256 gray scale.

Absolute fluctuating asymmetry (AFA) was calculated as the unsigned left $(L)$ minus right $(R)$ difference. Relative fluctuating asymmetry (RFA) was calculated as the absolute value 


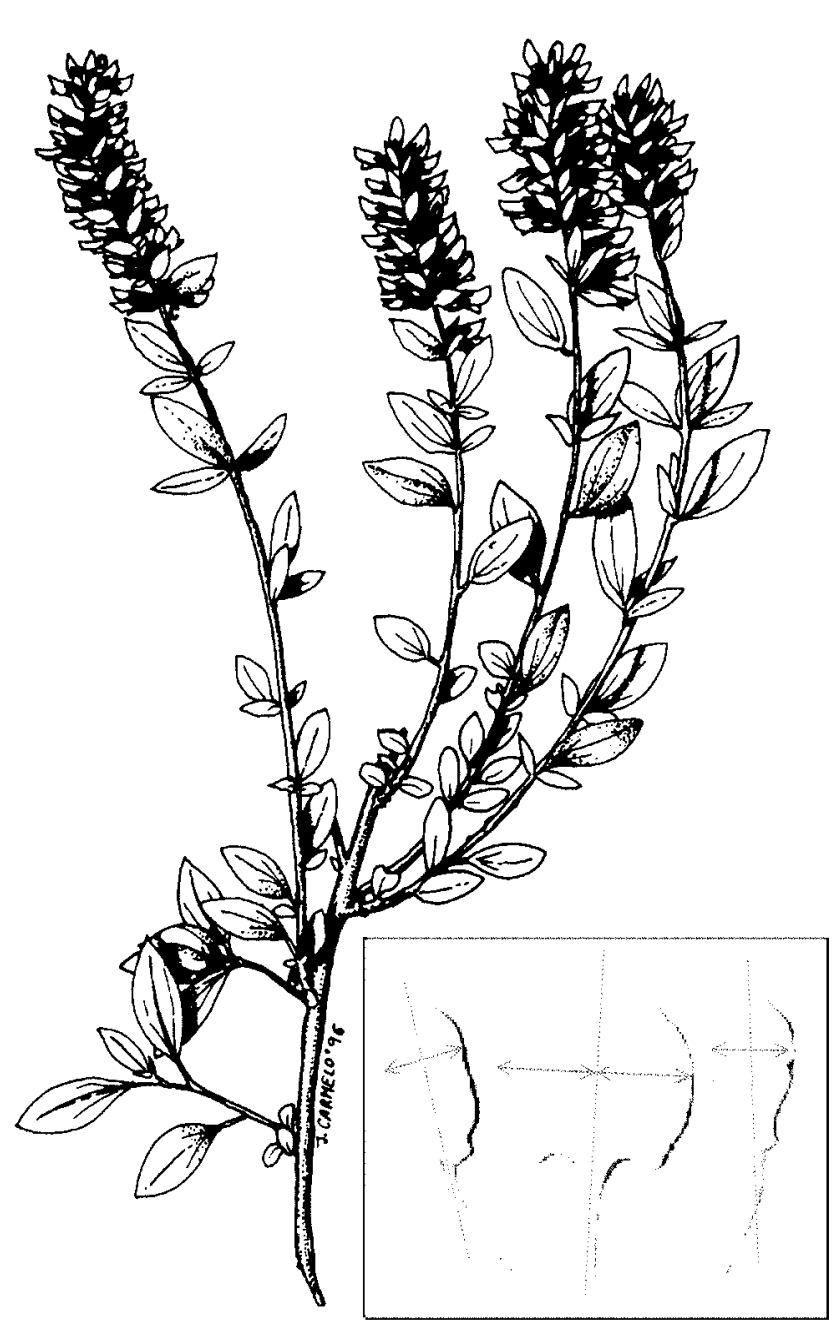

Fig. 1 Illustration of 2-yr-old branch of Anthyllis cytisoides. Inset, magnification of corolla parts: vexillum and alaes, showing left and right width measurements.

of left $(L)$ minus right $(R)$ divided by the average $(L+R) / 2$, to correct for possible associations between asymmetry and size (index F2 of Palmer and Strobeck 1986). We also used the variance of left and right traits (index F4 of Palmer and Strobeck 1986). The validity of fluctuating asymmetry interpretations depends on, according to Palmer and Strobeck (1986, 1992), an absence of directional asymmetry, antisymmetry (bimodality or platykurtosis), and a normal distribution for $(L-R)$ with mean zero. However, antisymmetry and directional symmetry are many times present, are difficult to distinguish from fluctuating asymmetry (Rowe et al. 1997), and may not be related to developmental error. Graham et al. (1998) proposed alternative approaches to estimate fluctuating asymmetry in situations where directional asymmetry or antisymmetry are present. In this study, we calculated the residual variance obtained from a principal component ANCOVA matrix on the two sides (left and right) of each floral trait. Given no measurement error, factor scores on the second principal component are estimates of fluctuating asymmetry.

Translational symmetry. We selected a developed new shoot per branch located in the second or third position from the previous year's stem. Later in the laboratory, we measured vegetative length (from shoot base to the inflorescence), inflorescence length, and internode length (distance between leaf insertions) from bottom to the top using an electronic caliper, recording to the nearest $0.01 \mathrm{~mm}$ (fig. 1).

In $A$. cytisoides, the relation between internode length and node order follows a self-similar sequence, where internode order declines regularly as we proceed up the stem (Alados et al. 1994; Escós et al. 1997, 2000). The relation between internode length $(L)$ and node order $(N)$, starting from the shoot base to the uppermost, fits the general equation

$$
L=\mathrm{kN}^{b} \mathrm{e}^{\mathrm{a} N}
$$

where $\mathrm{e}$ is the natural base and $k, a$, and $b$ are fitted constants. This equation has two components. The first component $\left(k N^{\mathrm{b}}\right)$ corresponds to the allometric relationship between internode length and node order (Escós et al. 1997). The second component $\left(\mathrm{e}^{-a N}\right)$ represents the inhibition mechanism patterns of flower formation (Meinhardt 1984). The use of this equation, however, does not imply biological meaning for parameter values; it is simply a convenient function that is able to express the differences between individuals.

The constants of the equation were obtained from regression analyses. Under stress, the impact of random perturbations increases, leading to enhanced developmental instability, that is, to a decrease in the accuracy of the curve fitting. Regressions were performed separately for each plant and the resulting $R^{2}$, $S_{\mathrm{yx}}$, and $S_{\mathrm{b}}$ were then analyzed. Because the number of internodes varies among shoots, we calculated $R^{2}$ adjusted to the degrees of freedom. The standard error of the parameter $b, S_{\mathrm{b}}$, is positively correlated with $b$ (Pearson's correlation coefficient, $r=0.37, P<0.001)$. In consequence, we used $S_{b} / b$ to avoid bias due to the relation between treatment effects and size. Finally, because $S_{y x}$ is related to average internode length, it was divided by $\bar{y}$ mean, $S_{y x} / \bar{y}$, following Zar's (1984) recommendations.

\section{Statistical Analysis}

To find out whether we have to correct for directional symmetry or antisymmetry, we performed two different kinds of analyses: (1) We first did normality tests on the distribution of signed $(L-R)$ differences to test the presence of systematic nondirectional (antisymmetry) or directional deviations from bilateral symmetry. Correlations between the magnitude of AFA, $|L-R|$, and character size, $(L+R)$, were also calculated to investigate the possible need for normalizing $|L-R|$ (Palmer 1994). (2) We did a mixed-model two-way ANOVA with side and treatment as fixed-effect factors. Side effects represent directional asymmetry, treatment effects represent size and shape variations, and the "side-by-treatment interaction" term represents antisymmetry (Palmer and Strobeck 1986). Individual variance, nested within the side-by-treatment interaction as a random effect factor, represents the nondirectional asymmetry. The error term refers to the measurement variation and represents the measurement error.

In order to investigate the variation in fluctuating asymmetry due to treatment, we performed two different analyses. (1) We 
did a mixed-model ANOVA, with two fixed-effect factors, and four levels nested analysis (transect nested in treatment, individual nested in transects, flower nested within individual, and measurement nested in flower as error term). We compared floral trait size in the same way. We used parametric statistics on raw data because they are robust to violations of normality assumptions and because transformations or the use of nonparametric tests result in loss of power (Gangestad and Thornhill 1998). (2) Within-trait variance was calculated from the side within flower term of the four nested ANOVAs, one per treatment. To determine robust probability values, we used a bootstrap procedure (Manly 1991), consisting of sampling with replacement from the observed distribution of untransformed data. An empirical distribution was created by repeatedly randomizing and reanalyzing. After 1000 random reanalyses, the actual MS (mean square of the side within flower term) value was compared to the distribution generated by the bootstrap procedure to determine the probability of obtaining a value of MS that large or larger. A $t$-test was used to compare the MS from the bootstrap distribution with the MS obtained from the different treatment.

Finally, in order to see the effect of treatments on curvefitting estimators $R^{2}, S_{y x} / \bar{y}, S_{b} / b$ and on the regression parameters $a, b$, and $\ln k$, a three-level nested ANOVA was performed, with transects nested within treatment, individuals nested within transects, and shoots nested within individuals as the error term.

Data were analyzed by Model III ANOVA (GLM routine [SAS Institute 1995]). Nested effects were pooled following recommendations of Sokal and Rohlf (1981). Comparisons of means between treatments were made using Tukey's Studentized range test.

\section{Results}

\section{Preliminary Floral Asymmetry Tests}

To detect factors confounding analyses of fluctuating asymmetry, a series of preliminary tests was performed on the distribution of signed asymmetry. Signed $(L-R)$, averaged for 704 alae pairs, gave a mean \pm SE of $0.37 \pm 0.14$, which differs significantly from zero $(t=2.66, P<0.05)$. The Wilks-Shapiro test value was $0.95(P<0.001)$. The signed difference between left and right of vexillum, averaged for the 704 flowers $(-0.55 \pm 0.17)$, also differed significantly from zero $(t=$ 3.31, $P<0.01)$. The Wilks-Shapiro statistic was $0.98(P<$ $0.05)$. Separate analyses were performed for the Almería and Málaga populations. Directional asymmetry calculated from the side factor of two-way ANOVA (side $\times$ treatment) indicated no directional asymmetry for alae $\left(F_{1,460}=0.90\right)$ or vexillum $\left(F_{1,460}=2.31\right)$ in the Almería population, at the 0.05 significance level. The side-by-treatment interaction, representing antisymmetry (Palmer and Strobeck 1986), was not significant for either alae $\left(F_{3,460}=1.24\right.$, ns $)$ or vexillum $\left(F_{3,460}=0.99, \mathrm{~ns}\right)$. Treatment effects significantly affected floral morphometry (half vexillum and alae widths), which represents size and shape variation in floral traits. Similar analyses were performed for the Málaga population and showed a lack of alae $\left(F_{1,232}=0.87, \mathrm{~ns}\right)$ and vexillum $\left(F_{1,232}=2.42, \mathrm{~ns}\right) \mathrm{di}-$ rectional asymmetry. Antisymmetry (side-by-treatment inter- action) was not significant, in any case, either for alae $\left(F_{1,232}=0.07, \mathrm{~ns}\right)$ or vexillum $\left(F_{1,232}=0.05, \mathrm{~ns}\right)$. That is, neither Almería nor Málaga populations presented directional asymmetry or antisymmetry.

The vexillum presented low trait size variability with a coefficient of variation equal to 10.84 . The frequency distribution of vexillum size was platykurtic at the 0.05 significance level $\left(g_{2}=-0.36, \operatorname{tg}_{2}=1.96, P=0.05\right)$ and skewed to the right $\left(g_{1}=0.23, \operatorname{tg}_{1}=2.46, P<0.05\right)$, indicating disruptive selection. Left and right alae size distributions also presented low coefficients of variation $(\mathrm{CV}=16.24$, for left alae; $\mathrm{CV}=$ 15.30 , for right alae) with leptokurtosis $\left(g_{2}=2.97, \operatorname{tg}_{2}=\right.$ 16.09, $P<0.001$, for left alae; $g_{2}=1.37, t g_{2}=7.42, P<$ 0.001 , for right alae) and right skewed $\left(g_{1}=0.88, \operatorname{tg}_{1}=\right.$ 9.53, $g_{1}=0.56, \operatorname{tg}_{1}=6.07, P<0.001$, for left and right alae, respectively), indicating stabilizing selection.

The ratio of measurement MS (mean square) to the amongindividual MS (MS due to treatment effects) represents the relative trait size variation due to measurement error and ranged between $0.86 \%$ for alae width to $1.00 \%$ of half vexillum width. The proportion of measurement MS to the individual within-trait MS (MS of individual within side-bytreatment interaction) represents the fraction of developmental instability variation due to measurement error. It was close to $4 \%(3.93 \%$ for half alae width and $4.33 \%$ for half vexillum width).

Size scaling appeared unnecessary for investigating vexilla, as the correlation between the magnitude of absolute fluctuating asymmetry and character size was not significant $(r=$ $-0.04, n=704$, ns). Alae, on the contrary, presented a significant Pearson's correlation coefficient between absolute fluctuating asymmetry and the sum of left plus right alaes $(r=$ $0.31, n=704, P<0.01)$. In consequence, we used relative fluctuating asymmetry in further analyses.

In order to control the possible effects of the observed directional asymmetry and antisymmetry, we performed a principal component ANCOVA matrix on the two sides of each floral trait analyzed for both populations clumped together. Because previous exploration of residuals showed an increase with size, we assumed a multiplicative error model and used the logarithm of left and right sides in the analysis (see Graham et al. 1998). The relationship between left and right alae fits the equation

$$
L_{\text {alae }}=1.12 R_{\text {alae }}^{1.04}
$$

while vexilla fit

$$
L_{\mathrm{vex}}=2.27 R_{\mathrm{vex}}^{0.75}
$$

where $L_{\text {alae }}$ and $R_{\text {alae }}$ represent left and right alae width, and $L_{\text {vex }}$ and $R_{\text {vex }}$ represent left and right vexillum width. Because the slope (1.04) does not differ significantly from 1.0 and $95 \%$ confidence limits are 0.94 and 1.15 , we presume that alae present isometric growth. Confidence limits for vexillum slope are 0.57 and 0.97, exhibiting anisometric growth. However, the low slope value compensates for the high intercept value, as demonstrated by the low vexillum skewness $(-0.17)$. The absolute value of factor scores on the second principal component, $\lambda_{2}$, represents the individual fluctuating asymmetry 
Table 1

Partitioning ANOVA with Two Fixed-Effect Factors (Location and Exposure) and Four-Level Nested Analysis

\begin{tabular}{|c|c|c|c|c|c|c|c|c|}
\hline \multirow[b]{2}{*}{ Source } & \multicolumn{2}{|c|}{$\mathrm{RFA}_{\text {alae }}$} & \multicolumn{2}{|l|}{$\mathrm{AFA}_{\text {vex }}$} & \multicolumn{2}{|c|}{$\lambda_{2}$ Alae } & \multicolumn{2}{|c|}{$\lambda_{2} \operatorname{Vex}$} \\
\hline & df & $F$ & df & $F$ & $\mathrm{df}$ & $F$ & df & $F$ \\
\hline Exposure $(E)$ & $(1,472)$ & $3.89^{*}$ & $(1,472)$ & 1.47 & $(1,472)$ & $3.88^{*}$ & $(1,1)$ & 0.98 \\
\hline Location $(L)$ & $(1,472)$ & 0.07 & $(1,472)$ & 0.05 & $(1,472)$ & 0.12 & $(1,1)$ & 0.00 \\
\hline Interaction & $(1,472)$ & 0.006 & $(1,472)$ & 0.58 & $(1,472)$ & 0.73 & $(1,472)$ & $3.54^{* *}$ \\
\hline$T \subset L \times E$ & $(4,468)$ & 1.42 & $(4,111)$ & 0.49 & $(4,468)$ & 1.54 & $(4,111)$ & 1.27 \\
\hline$I \subset T$ & $(111,119)$ & 0.94 & $(111,119)$ & $1.78^{*}$ & $(111,119)$ & 0.88 & $(111,119)$ & $1.83^{* *}$ \\
\hline$F \subset I$ & $(119,238)$ & $14.6^{* *}$ & $(119,238)$ & $3.55^{* *}$ & $(119,238)$ & $15.85^{* *}$ & $(119,237)$ & $3.4^{* *}$ \\
\hline
\end{tabular}

Note. Transect $(T)$ is nested within location-exposure interaction $(T \subset L \times E)$, individuals are nested with transects $(I \subset T)$, and flower is nested within individuals $(F \subset I)$. Measurement error was the error term. Dependent variable is relative fluctuating asymmetry of alae $\left(\mathrm{RFA}_{\mathrm{alae}}\right)$, absolute fluctuating asymmetry of vexillum $\left(\mathrm{AFA}_{\mathrm{vex}}\right)$, and residual variance of alae and vexillum $\left(\lambda_{2}\right.$ Alae, $\lambda_{2}$ Vex $)$. Absence of asterisks indicates $P>0.05$.

${ }^{*} P<0.05$

${ }^{* *} P<0.01$.

(Graham et al. 1998) and was used as the dependent variable in the mixed-model ANOVA.

\section{Fluctuating Asymmetry}

The results shown in table 1 reveal that alae asymmetry was significantly related with slope aspect, whatever the index used. South-exposed plants presented lower asymmetry than northexposed plants. No significant differences between locations existed. Vexillum asymmetry did not vary significantly with either exposure or location when ANOVA was performed. Mean fluctuating asymmetry values for the different indices used are presented in table 2 . The larger differences observed correspond to the F4 index (within side MS).

$\mathrm{MS}_{\text {alae }}$ (F4 index) for south-exposed plants presented significantly lower fluctuating asymmetry than expected based on the bootstrap distributions for Almería $(t=8.96, P<0.001)$ and Málaga $(t=4.66, P<0.001)$. However, no significant differences were observed when plants were north exposed ( $t=1.10$, ns, for Almería; $t=1.79$, ns, for Málaga). Comparisons between treatment $\mathrm{MS}_{\text {alae }}$ revealed that Almería southexposed plants are more symmetrical than Almería northexposed plants. The same results were observed for Málaga plants, i.e., alaes being more symmetrical when south exposed (table 2).

$\mathrm{MS}_{\mathrm{vex}}$ presents a different tendency, exhibiting increasing asymmetry for south-exposed plants (table 2). Málaga and Almería south-exposed vexilla are significantly more asymmetrical than that expected from the bootstrap distribution ( $t=6.40, P<0.001 ; t=2.14, P<0.05$, respectively), while north-exposed Málaga plants presented the most symmetrical vexilla $(t=3.41, P<0.01)$.

Average \pm SE values of floral trait sizes for north- and southexposed slopes at Almería and Málaga are presented in table 1. The results show that floral trait size was significantly affected by location $\left(F_{1,472}=28.6\right.$, for vexillum; $F_{1,472}=26.6$, for left alae; $F_{1,472}=22.8$, for right alae, all significant at the 0.001 level), with Málaga flowers larger than Almería flowers for all traits.

\section{Translational Symmetry}

The curve-fitting accuracy of the relationships between internode length and node order is presented in table 4 and figure 2 , for each treatment separately. The parameter $b$ represents the rate of internode enlargement with node order, which

Table 2

Means \pm SE of Anthyllis cytisoides Floral Traits Inhabiting Almería and Málaga under North and South Slope Exposures

\begin{tabular}{|c|c|c|c|c|}
\hline \multirow[b]{2}{*}{ Trait } & \multicolumn{2}{|c|}{ Almería } & \multicolumn{2}{|c|}{ Málaga } \\
\hline & North $(n=120)$ & South $(n=120)$ & North $(n=116)$ & South $(n=120)$ \\
\hline $\mathrm{RFA}_{\text {alae }}$ & $0.114 \pm 0.01^{\mathrm{A}}$ & $0.095 \pm 0.007^{\mathrm{A}}$ & $0.109 \pm 0.01^{\mathrm{A}}$ & $0.095 \pm 0.008^{\mathrm{A}}$ \\
\hline $\mathrm{AFA}_{\mathrm{vex}}$ & $3.13 \pm 0.24^{\mathrm{A}}$ & $3.24 \pm 0.28^{\mathrm{A}}$ & $2.99 \pm 0.18^{\mathrm{A}}$ & $3.51 \pm 0.30^{\mathrm{A}}$ \\
\hline$\lambda_{2}$ alae & $0.084 \pm 0.007^{\mathrm{A}}$ & $0.066 \pm 0.005^{\mathrm{B}}$ & $0.076 \pm 0.01^{\mathrm{AB}}$ & $0.069 \pm 0.005^{\mathrm{AB}}$ \\
\hline$\lambda_{2}$ vex & $0.084 \pm 0.007^{\mathrm{A}}$ & $0.077 \pm 0.007^{\mathrm{A}}$ & $0.070 \pm 0.004^{\mathrm{A}}$ & $0.090 \pm 0.007^{\mathrm{A}}$ \\
\hline Left alae & $24.02 \pm 0.34^{\mathrm{A}}$ & $25.37 \pm 0.34^{\mathrm{B}}$ & $26.77 \pm 0.49^{\mathrm{C}}$ & $26.54 \pm 0.35^{\mathrm{BC}}$ \\
\hline Right alae & $24.65 \pm 0.40^{\mathrm{A}}$ & $24.27 \pm 0.31^{\mathrm{A}}$ & $26.34 \pm 0.35^{\mathrm{B}}$ & $25.95 \pm 0.35^{\mathrm{B}}$ \\
\hline Vexillum & $52.39 \pm 0.48^{\mathrm{A}}$ & $55.38 \pm 0.48^{\mathrm{B}}$ & $59.42 \pm 0.50^{\mathrm{C}}$ & $59.36 \pm 0.50^{\mathrm{C}}$ \\
\hline $\mathrm{MS}_{\text {alae }}$ & $17.22^{\mathrm{A}}$ & $10.48^{\mathrm{B}}$ & $18.77^{\mathrm{A}}$ & $12.18^{\mathrm{B}}$ \\
\hline $\mathrm{MS}_{\text {vex }}$ & $14.95^{\mathrm{A}}$ & $17.34^{\mathrm{AB}}$ & $10.15^{\mathrm{C}}$ & $21.57^{\mathrm{B}}$ \\
\hline
\end{tabular}

Note. Means squares (MS) are tested with $t$-test. Means with different letters are significant at the 0.05 level, Tukey's Studentized range test. 


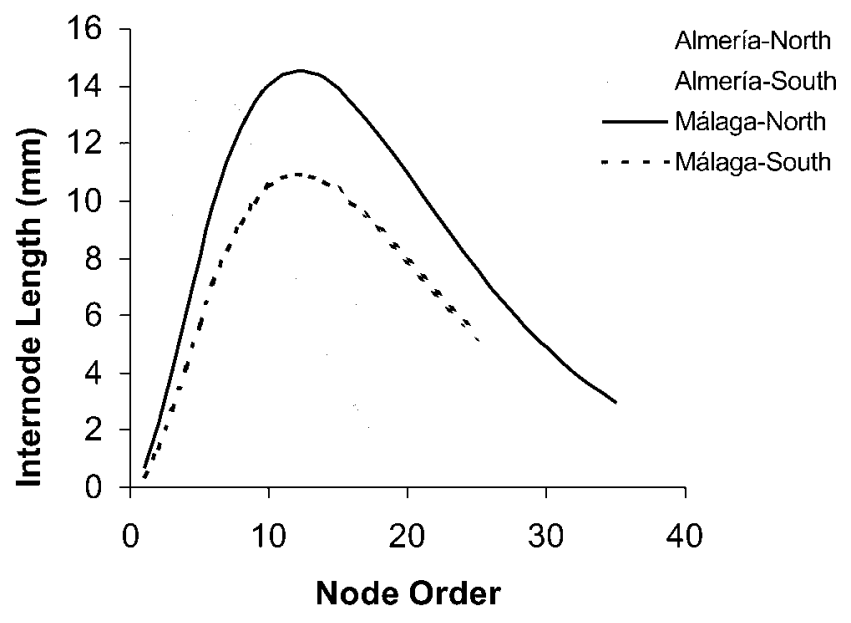

Fig. 2 Scatterplots of nonlinear best-fit equation $L=\mathrm{kN}^{\mathrm{b}} \mathrm{e}^{-\mathrm{aN}}$ for internode length versus node order for Almería and Málaga population, north and south exposed.

changes significantly with treatment $\left(F_{3,314}=9.70, P<0.001\right)$, increasing in the south-exposed plants. The parameter $a$, representing the inhibition mechanism of the growth pattern, describes internode shrinking along the stem. In consequence, the larger the absolute value of $a$, the more pronounced is the shortening. The parameter $a$ varied significantly between treatments $\left(F_{3,314}=57.90, P<0.001\right)$, reaching its largest absolute value in Almería south-exposed plants and the lowest in Málaga north-exposed plants (table 4). A clear picture of the morphological aspect that produces the variations in the parameter values averaged per treatment effect is presented in figure 2 . This figure shows that shoots produced by plants living in Málaga grew more slowly during the first internodes, and as node order progressed, the decline in internode length with order was less steep. In contrast, in Almería internode length dropped drastically after a few internodes. The total length $(\mathrm{mm})$ reached at the end of the seasonal growth period was larger in north-exposed Málaga plants $(374.6 \pm 7.7 ; 80)$ than south-exposed Almería (208.2 $\pm 9.0 ; 80)$.

To determine how exposure affects the translational symmetry of internode length, we performed nested ANOVA with the adjusted coefficient of determination, $\mathrm{R}^{2}$, standard error of the regression, $S_{y x} / \bar{y}$, and standard error of the parameter $b, S_{b} / b$, as dependent variables (table 3 ). The results presented in table 4 show a lower value for $R^{2}$ and a higher $S_{y x} / \bar{y}$, indicating lower developmental instability in the Almería than in the Málaga population. The worst fit was observed in the south-exposed Málaga plants. The worst fit for $S_{b} / b$ also was found in the south-exposed Málaga plants. No difference among transect within treatment occurred, and variation among shoots within individuals was lower (i.e., MS is 0.015 for the $R^{2}$ ) than variation between individuals within transects (MS is 0.036 for the $R^{2}$ ). We can ascribe differences among the treatments to main effects. Comparisons between means were assessed by Tukey's Studentized range test (table 4).

Because only vegetative growth pattern was measured in plants collected in 1995, we assessed curve-fitting accuracy of the reduced equation $\left(L=k N^{b}\right)$, which corresponds to vegetative growth. To do that, we calculated the equation parameters from the vegetative part of the shoot, dismissing the inflorescence. Previous analysis revealed that the adjusted coefficients of determination $\left(R^{2}\right)$ obtained from the extended equation (1) and the reduced equation were highly correlated (Pearson's correlation coefficient $r=0.70, P<0.001, n=$ 160). Similar results were obtained for the parameter $b(r=$ 0.76, $P<0.001, n=160$ ).

Comparisons of plant response after dry versus mesic years revealed that in Almería, south-exposed plants were developmentally more stable than north-exposed plants, with that tendency being more pronounced after a dry 1995 year. On the contrary, Málaga north-exposed plants demonstrated less stress than south-exposed plants after a dry year, with this trend disappearing after a humid period (1997) (fig. 3). That is, a significant interaction exists between location, year, and exposure $\left(F_{1,308}=8.24, P<0.01\right)$. Separate analyses for Almería and Málaga populations reveal a significant effect of average annual rainfall in Almería, with plants less stressed after a humid year (means \pm SE are $0.78 \pm 0.01$ for 1997 , $0.70 \pm 0.03$ for $\left.1995 ; F_{1,154}=4.77, P<0.05\right)$. On the contrary, no significant difference between years occurred in the Málaga population $\left(F_{1,154}=1.21\right.$, ns), while there was a significant interaction between exposure and year $\left(F_{1,154}=6.76\right.$, $P<0.05)$.

Total shoot length was significantly lower in the drier 1995 than in $1997\left(F_{1,309}=220.52, P<0.001\right)$ for both the Málaga and Almería populations and for both the north- and southexposed populations.

Table 3

Partitioning ANCOVA with One Fixed-Effect Factor (Location $\times$ Exposure) and Three-Level Nested Analysis

\begin{tabular}{|c|c|c|c|c|c|c|}
\hline \multirow[b]{2}{*}{ Source } & \multicolumn{2}{|c|}{$R^{2}$} & \multicolumn{2}{|c|}{$S_{y x} / \bar{y}$} & \multicolumn{2}{|c|}{$S_{b} / b$} \\
\hline & $\mathrm{df}$ & $F$ & $\mathrm{df}$ & $F$ & $\mathrm{df}$ & $F$ \\
\hline $\begin{array}{l}L \times E \\
(T \subset L \times E) \\
(I \subset T)\end{array}$ & $\begin{array}{r}(3,314) \\
(4,151) \\
(151,159)\end{array}$ & $\begin{array}{c}13.73^{* *} \\
0.27 \\
2.38^{* *}\end{array}$ & $\begin{array}{r}(1,314) \\
(4,151) \\
(151,159)\end{array}$ & $\begin{array}{c}124.84^{* *} \\
0.60 \\
2.68^{* *}\end{array}$ & $\begin{array}{r}(1,314) \\
(4,151) \\
(151,159)\end{array}$ & $\begin{array}{l}5.00^{* *} \\
0.98^{* *} \\
3.18^{* *}\end{array}$ \\
\hline
\end{tabular}

Note. $\quad L=$ location, $E=$ exposure. Transect $(T)$ is nested within location-exposure interaction $(T \subset L \times E)$, individual is nested within transect $(I \subset T)$, and shoot nested within individuals as error term. Dependent variables are $R_{2}, S_{y x} / \bar{y}$, and $S_{b} / b$ for Almería and Málaga population under north and south exposures. Absence of asterisks indicates $P>0.05$.

${ }^{* *} P<0.01$. 
Table 4

Means \pm SE Values of Dependent Variables and Equation Parameters Are Present for Each Treatment Effect

\begin{tabular}{lrrrrr}
\hline & \multicolumn{2}{c}{ Málaga } & & \multicolumn{2}{c}{ Almería } \\
\cline { 2 - 3 } \cline { 5 - 6 } & North $(n=80)$ & South $(n=78)$ & & North $(n=80)$ & \multicolumn{1}{c}{ South $(n=80)$} \\
\hline$R^{2}$ & $0.65 \pm 0.01^{\mathrm{A}}$ & $0.56 \pm 0.01^{\mathrm{B}}$ & & $0.67 \pm 0.02^{\mathrm{A}}$ & $0.71 \pm 0.02^{\mathrm{A}}$ \\
$S_{y x} / \bar{y}$ & $0.26 \pm 0.01^{\mathrm{A}}$ & $0.41 \pm 0.01^{\mathrm{B}}$ & & $0.19 \pm 0.01^{\mathrm{C}}$ & $0.20 \pm 0.01^{\mathrm{C}}$ \\
$S_{b} / b$ & $0.14 \pm 0.001^{\mathrm{A}}$ & $0.19 \pm 0.01^{\mathrm{B}}$ & & $0.18 \pm 0.02^{\mathrm{B}}$ & $0.17 \pm 0.01^{\mathrm{AB}}$ \\
$b$ & $1.95 \pm 0.05^{\mathrm{A}}$ & $2.18 \pm 0.04^{\mathrm{B}}$ & & $1.92 \pm 0.07^{\mathrm{A}}$ & $2.32 \pm 0.07^{\mathrm{B}}$ \\
$a$ & $-0.16 \pm 0.01^{\mathrm{A}}$ & $-0.18 \pm 0.01^{\mathrm{A}}$ & & $-0.27 \pm 0.01^{\mathrm{B}}$ & $-0.39 \pm 0.02^{\mathrm{C}}$ \\
$\ln k$ & $-0.25 \pm 0.11^{\mathrm{A}}$ & $-0.86 \pm 0.04^{\mathrm{B}}$ & & $0.86 \pm 0.07^{\mathrm{C}}$ & $0.85 \pm 0.06^{\mathrm{C}}$ \\
\hline
\end{tabular}

Note. Means with different letters are significant at the 0.05 level, Tukey's Studentized range test.

\section{Discussion}

Knowledge of the capacity of long-lived species such as $A n-$ thyllis cytisoides to adjust to environmental changes is critical because of the importance of such species in preventing soil erosion. In this study, we observed that translational symmetry varied in north- and south-exposed plants but differently between the Almería and Málaga populations. We observed that developmental stability was enhanced in south-exposed plants in the population inhabiting the more xeric habitat (Almería) after both dry and humid periods. In contrast, A. cytisoides living in a subhumid habitat did not alter their developmental stability in response to exposure after a humid period but exhibited a decline in stability on south-exposed slopes after a dry period. That is interpreted as a consequence of the response of $A$. cytisoides to aridity. Plants that are habituated to long periods of aridity present a conservative, slow-growth strategy and modify their allocation patterns in response to water deficit; i.e., saving energy in production (low growth rate) allows the plant to transfer energy to homeostasis (developmental stability). This conservative strategy has been called "stress resistance syndrome" (Grime and Hunt 1975; Grime 1979; Chapin et al. 1993), and it is frequently found among plants in dry areas (Edelin 1977; Thomansson 1977). When the same species grows in more benign habitats (Málaga), extreme drought conditions, as seen in 1995, make the plants on south-facing slopes developmentally less stable because the reduction in growth rate is not enough to compensate for the energy required for homeostasis during development. That is, the Málaga population presents a competitive strategy that makes $A$. cytisoides less resistant to dry periods. An association of high developmental instability and increased growth also has been observed in nutrient fertilization experiments (Møller 1995; Andalo et al. 2000; Lappalainen et al. 2000).

Corroborating former results, we observed that some phenomorphological features of $A$. cytisoides also varied along a precipitation gradient. Plants inhabiting xeric areas (Almería) started growing sooner (Navarro et al. 1993) than plants living in a subhumid climate (Málaga) (Hidalgo and Cabezudo 1994), with earlier apex inhibition and a lower number of internodes. As a result, Málaga shoots reached larger size than Almería shoots. Additionally, north-exposed plants, growing for a longer period and with lower inhibition, reached larger size than south-exposed plants. That is, A. cytisoides reduced shoot enlargement in response to water deficit. This effect was more evident under mild weather conditions (Málaga) than under the extreme xeric conditions of Almería. Microgeographical experiments in Israel revealed that microclimatic variation in opposite slopes appeared as an evolutionary driving force of genotypic and phenotypic evolution Nevo (1997, 1998). Thus, under extreme environmental conditions the potential for evolutionary change was low because of the high cost associated with the accommodation to environmental stress. In other words, plants from less stressful environments had a broader reaction norm (Stearns 1989; Parsons 1994).

In summary, A. cytisoides accustomed to xeric stress are less likely to exhaust water resources, while plants with high growth rates have high intrinsic respiration requirements that cannot be supported when water is scarce. Prolonged drought

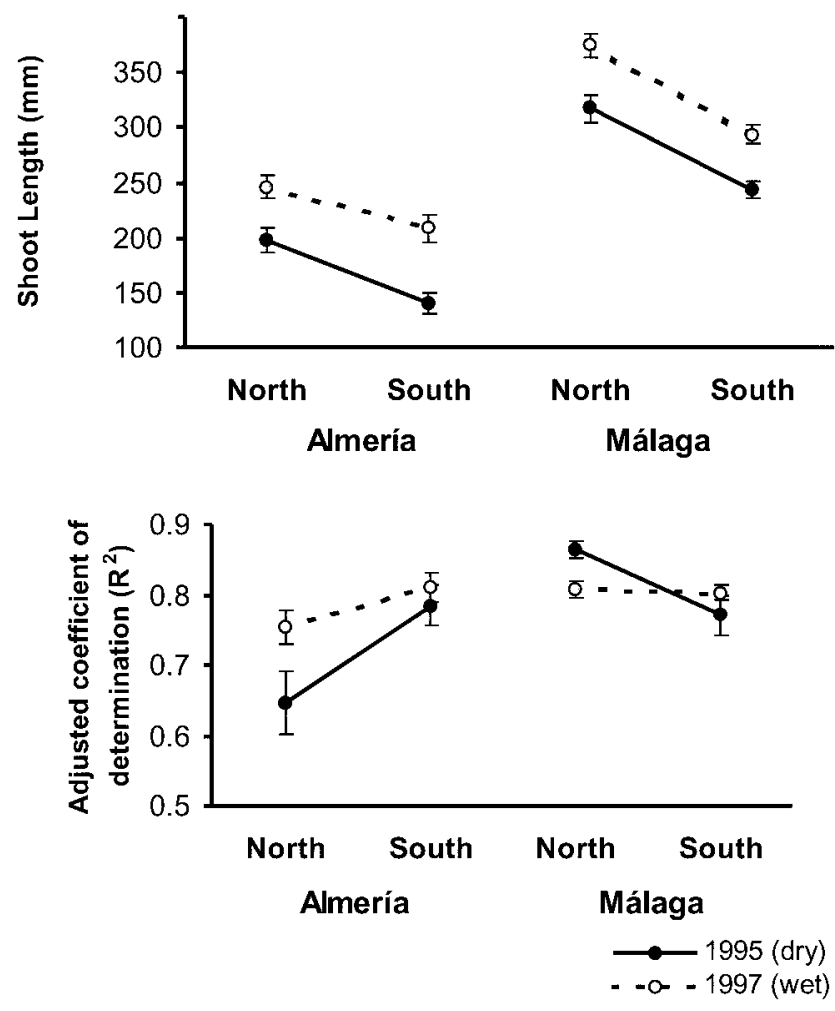

Fig. 3 Comparative effects of water deficit on developmental stability (adjusted coefficient of determination $R^{2}$ ) and growth (shoot length) of Anthyllis cytisoides. 
exposure enables the plant to make physiological and morphological adjustments that allow for normal functioning even while the stresses persist. By reducing shoot elongation and energy/nutrient allocation to reproduction the plant can ameliorate stress by reducing nutrient demand, allowing it to maintain a steady supply of nutrients for restoring and maintaining homeostasis under environmental stress.

Alae floral asymmetry also increased in north-exposed plants in both the Almería and Málaga populations, both with respect to traditional relative fluctuating asymmetry and in terms of the directional component of asymmetry, as measured with residual variance. That is, south exposure enhanced floral homeostasis. However, these indexes of stress were less sensitive to environmental change than translational asymmetry of vegetative structures.

Fitness depends on the phenotypic expression of traits that are functionally important to the organism. Consequently, natural selection should act to minimize the developmental error of such traits (Fowler and Whitlock 1994). Previous studies have reported adult survival to be more important than reproduction to the total inclusive fitness of A. cytisoides (Escós et al. 1997). Consequently, we may expect higher canalization of traits that enhance adult survival in comparison with floral asymmetries. Given that allometric relations between plant parts are important in order to sustain plant mechanical stability (Niklas 1992; Niklas and Buchman 1994), they must be maintained during growth. It is, therefore, not surprising that translational symmetry presented a lower variation coefficient $\left(\mathrm{CV}=24.66\right.$ for $R^{2}$ and 27.23 for the scaling parameter $b$ ) than floral asymmetries. Similar results were observed in Cistus ladanifer $\mathrm{L}$. (CV $=34$ for the standard error of the regression; Alados et al. 1999). In contrast, we observed high variability of floral asymmetries in this study (variation coefficient of vexillum $\mathrm{AFA}_{\text {vex }}$ is 87.61 and 90.85 for $\mathrm{RFA}_{\text {alae }}$ ) in comparison with the values observed for floral asymmetry of $C$. ladanifer $(\mathrm{CV}=55)$ and close to the one observed in the leaves of the same species $(C V=84)$. This makes sense because $C$. ladanifer and A. cytisoides have different types of corollas according to their mode of pollination and their functional structure. $\mathrm{Zy}-$ gomorphy has evolved from actinomorphy by establishment of a reflectional symmetry and has been suggested to promote specialist pollinators such as bees, which are more efficient than generalist pollinators (Cronk and Möller 1997). Recently, evolved genotypes may be responsible for the larger developmental instability observed in zygomorphic corollas, as occurred in the gynodioecious Teucrium lusitanicum Schreb. where recently evolved male sterile individuals are more asymmetric that hermaphrodites (Alados et al. 1998b).

Leptokurtosis is more pronounced in bilaterally symmetrical organs where selection acts to minimize asymmetry (Leung and Forbes 1997). We observed leptokurtosis in floral asymmetries of $A$. cytisoides, indicating the existence of selection mechanisms for symmetrical flowers. Leptokurtosis also was observed in the petals of 22 plant species (Møller and Shykoff 1999). The lack of relationship between vexillum size and asymmetry and the fact that vexillum size is platykurtic and skewed to the right demonstrates the existence of disruptive selection in vexillum size. That, together with the larger developmental stability of vexilla in north-exposed areas, is in accordance with the functional value of the vexillum both in the protection of flower buds (Tucker 1987) and as an attractant to pollinators. Indeed, the size of floral parts in Papillonaceae flower types is genetically correlated with other floral features, such as production and size of pollen (Primak 1987). Nectar production, the principal floral reward in Anthyllis, is also correlated with petal size (Herrera 1985; Petanidou and Smets 1995). Alae size is leptokurtic and positively correlated with asymmetry, indicating a stabilizing and directional selection for symmetrical and small alae that is enhanced by the favorable effect of light on flower formation on south-facing slopes.

\section{Acknowledgments}

We are grateful to John Graham and Miguel Angel Quesada for critically reading the manuscript and making helpful suggestions. Manuela Vega, head of imaging analysis services at Málaga University, helped with image processing and floral measurement. The work was supported by the Comision Interministerial de Ciencia y Tecnología (AMB93-0777-C02-01). The support from both programs is gratefully acknowledged.

\section{Literature Cited}

Alados CL, JM Emlen, B Wachocki, CD Freeman 1998a Instability of development and fractal architecture in dryland plants as an index of grazing pressure. J Arid Environ 38:63-76.

Alados CL, J Escós, JM Emlen 1993 Developmental instability as an indicator of environmental stress in the Pacific hake (Merluccius productus). Fish Bull 91:587-593.

1994 Scale asymmetry: a tool to detect developmental instability under the fractal geometry scope. Pages 25-36 in MM Novak, ed. Fractals in the natural and applied sciences. Elsevier, Amsterdam.

Alados CL, T Navarro, B Cabezudo 1999 Tolerance assessment of Cistus ladanifer to serpentine soils by developmental stability analysis. Plant Ecol 143:51-66.

Alados CL, T Navarro, B Cabezudo, JM Emlen, CD Freeman $1998 b$ Developmental instability in gynodioecious Teucrium lusitanicum. Evol Ecol 12:21-34.

Andalo C, A Bazin, JA Shykoff 2000 Is there a genetic basis for fluctuating asymmetry and does it predict fitness in the plant Lotus corniculatus grown in different environmental conditions? Int J Plant Sci 161:213-220.

Anne P, F Mawri, S Gladstone, DC Freeman 1998 Is fluctuating asymmetry a reliable biomonitor of stress? a test using life history parameters in soybean. Int J Plant Sci 159:559-565.

Arroyo MTK 1981 Breeding systems and pollination biology in Leguminosae. Pages 723-769 in RM Polhill, PH Raven, eds. Advances in legume systematics. Pt 2. Royal Botanic Gardens, Kew.

Ayyad MAG, RL Dix 1964 An analysis of a vegetation microenvironmental complex on prairie slopes in Saskatchewan. Ecol Monogr 34:421-442.

Barroso F 1991 Estudio sobre el comportamiento alimentario y social de la cabra doméstica en el sureste árido español. PhD thesis. Granada University.

Bertness MD, RM Callaway 1994 Positive interactions in communities. Trends Ecol Evol 9:191-193. 
Chapin FS III 1980 The mineral nutrition of wild plants. Annu Rev Ecol Syst 11:233-260.

Chapin FS 1991 Integrated responses of plants to stress. BioScience 41:29-36.

1988 Ecological aspects of plant mineral nutrition. Adv Miner Nutr 3:161-191.

Chapin FS, K Autumn, F Pugnaire 1993 Evolution of suites of traits in response to environmental stress. Am Nat 142(suppl):S78-S92.

Clarke GM 1993 Fluctuating asymmetry of invertebrate populations as a biological indicator of environmental quality. Environ Pollut 82:207-211.

Coxson DS, JHH Looney 1986 Vegetation patterns within southern Alberta coulees. Can J Bot 64:2464-2475.

Cronk Q, M Möller 1997 Genetics of floral symmetry revealed. Trends Ecol Evol 12:85-86.

Edelin C 1977 Images de l'architecture des coniferes. These de 3eme cycle. VSTL, Montpellier. 255 pp.

Escós J, CL Alados, JM Emlen 1995 Fractal structures and fractal functions as disease indicators. Oikos 74:310-314.

1997 Grazing impact on plant fractal architecture and fitness of a Mediterranean shrub (Anthyllis cytisoides). Funct Ecol 11: 66-78.

Escós JM, CL Alados, F Pugnaire, J Puigdefabregas 2000 Interaction between development and environmental stress in arid-land shrubs. J Arid Environ 45:325-336.

Fowler K, MC Whitlock 1994 Fluctuating asymmetry does not increase with moderate inbreeding in Drosophila melanogaster. Heredity $73: 373-376$.

Freeman DC, JH Graham, JM Emlen 1993 Developmental stability in plants: symmetries, stress and epigenesis. Genetica 89:97-119.

Freeman DC, JH Graham, M Tracy, JM Emlen, CL Alados 1999 Developmental instability as a means of assessing stress in plants: a case study using electromagnetic fields and soybeans. Int J Plant Sci 160(suppl):S157-S166.

Gallacher AA, JI Sprent 1978 The effect of different water regimes on growth and nodule development of greenhouse growth Vicia faba. J Exp Bot 29:413-423.

Gangestad SW, R Thornhill 1998 The analysis of fluctuating asymmetry redux: the robustness of parametric statistics. Anim Behav 55:497-501.

Graham JH, JM Emlen, DC Freeman, LJ Leamy, JA Kieser 1998 Directional asymmetry and the measurement of developmental stability. Biol J Linn Soc 64:1-16.

Graham JH, DC Freeman, JM Emlen 1993 Developmental stability: a sensitive indicator of population under stress. Pages 136-158 in WG Landis, JS Hughes, MA Lewis, eds. Environmental toxicology and risk assessment: ASTM STP 1179. American Society for Testing and Materials, Philadelphia.

Grime JP 1979 Plant strategies and vegetation processes. Wiley, Chichester. 222 pp.

Grime JP, R Hunt 1975 Relative growth-rate: its range and adaptive significance in a local flora. J Ecol 63:393-422.

Herrera J 1985 Nectar secretion patterns in southern Spanish Mediterranean shrublands. Isr J Bot 34:47-58.

Hidalgo MI, B Cabezudo 1994 Producción de nectar en matorrales del sur de España (Andalucia). Acta Bot Malacitana 20:123-132.

Lappalainen JH, J Martel, K Lempa, B Wilsey, V Ossipov 2000 Effects of resource availability on carbon allocation and developmental instability in cloned birch seedlings. Int J Plant Sci 161: 119-125.

Leung B, MR Forbes 1997 Modelling fluctuating asymmetry in relation to stress and fitness. Oikos 78:397-405.

Levitt J 1980 Response of plants to environmental stresses: water, radiation salt and other stresses. Academic Press, New York. 607 pp.
Ludwig W 1932 Das Rechts-Links Problem im Tierrreich und beim Menschen. Springer, Berlin.

Manly BFJ 1991 Randomization and Monte Carlo methods in biology. Chapman \& Hall, London.

Markow TA 1995 Evolutionary ecology and developmental stability. Annu Rev Entomol 40:105-120.

Meinhardt H 1984 Models of pattern formation and their application to plant development. Pages 1-32 in PW Barlow, DJ Carr, eds. Positional controls in plant development. Cambridge University Press, Cambridge.

Møller AP 1995 Bumblebee preference for symmetrical flowers. Proc Natl Acad Sci USA 92:2288-2292.

Møller AP, A Pomiankowski 1993 Fluctuating asymmetry and sexual selection. Genetica 89:267-279.

Møller AP, JA Shykoff 1999 Morphological developmental stability in plants: patterns and causes. Int J Plant Sci 160(suppl):S135-S146.

Møller AP, JP Swaddle 1997 Asymmetry, developmental stability, and evolution. Oxford University Press, Oxford.

Møller AP, R Thornhill 1998 Bilateral symmetry and sexual selection: a meta-analysis. Am Nat 151:174-192.

Navarro T, JM Nieto-Caldera, A Perez-La-Torre, B Cabezudo 1993 Estudios fenomorfológicos en la vegetación del sur de España. III. Comportamiento estacional de una comunidad de badlands (Tabernas, Almeria, España). Acta Bot Malacitana 18:189-198.

Nevo E 1997 Evolution in actino across phylogeny caused by microclimatic stress at "Evolution Canyon." Theor Popul Biol 52: 231-243.

1998 Molecular evolution and ecological stress at global, regional and local scales: the Israeli perspective. J Exp Zool 282: 95-119.

Niklas KJ 1992 Plant biomechanics: an engineering approach to plant form and function. University of Chicago Press, Chicago.

Niklas KJ, SL Buchman 1994 The allometry of Saguaro height. Am J Bot 8:1161-1168.

Palmer AR 1994 Fluctuating asymmetry analyses: a primer. Pages 335-364 in TA Markow, ed. Developmental instability: its origins and evolutionary implications. Kluwer, Dordrecht.

Palmer AR, C Strobeck 1986 Fluctuating asymmetry: measurement, analysis, patterns. Annu Rev Ecol Syst 17:391-421.

1992 Fluctuating asymmetry as a measure of developmental stability: implications of non-normal distributions and power of statistical tests. Acta Zool Fenn 191:57-72.

Parsons PA 1990 Fluctuating asymmetry: an epigenetic measure of stress. Biol Rev 65:131-145.

1994 Developmental variability and the limits of adaptation: interaction with stress. Pages 247-256 in TA Markow, ed. Developmental instability: its origins and evolutionary implications. Kluwer, Dordrecht.

Petanidou T, E Smets 1995 The potential of marginal lands for bees and apiculture: nectar secretion in Mediterranean shrublands. Apidologie 26:39-52.

Primak RB 1987 Relationships among flowers, fruits and seeds. Annu Rev Ecol Syst 18:409-430.

Puigdefábregas J, JM Alonso, JA Brenner, SC Clark, F Domingo, M Cueto, L Gutiérrez, et al 1996 Interactions of soil and vegetation along a catena in semiarid Spain. Pages 137-168 in J Thornes, J Brandt, eds. Mediterranean desertification and land use. Wiley, New York.

Rowe L, RR Repasky, AR Palmer 1997 Size-dependent asymmetry: fluctuating asymmetry versus antisymmetry and its relevance to condition-dependent signaling. Evolution 51:1401-1408.

Sherry RA, EM Lord 1996 Developmental stability in leaves of Clarkia tembloriensis (Onagraceae) as related to population outcrossing rates and heterozygosity. Evolution 50:80-91.

Sokal RR, FJ Rohlf 1981 Biometry. WH Freeman, New York. 859 pp. 
Soulé ME 1967 Phenetics of natural populations. II. Asymmetry and evolution in a lizard. Am Nat 101:141-160.

Sprent JJ 1972 The effects of water stress on nitrogen-fixing root nodules. New Phytol 71:443-450.

SAS Institute 1995 SAS/STAT user's guide, version 6. SAS Institute, Cary, N.C.

Stearns SC 1989 The evolutionary significance of phenotypic plasticity. BioScience 39:436-445.

Thomansson H 1977 Ecomorphologie et port des végétaux: example de quelques formations ligneuses de Madagascar. Bulletin du Museum de la Historie Naturelle Paris, 3 sér, no 460. Botanique 31: $49-69$.
Tilman D, JA Downing 1994 Biodiversity and stability in grasslands. Nature 367:363-365.

Tucker C 1987 Floral initiation and development legumes. Pages 183-239 in CH Stirton, ed. Advances in legume systematics. Pt 3. Royal Botanic Gardens, Kew.

Van Valen L 1962 A study of fluctuating asymmetry. Evolution 16: $125-142$.

Watson PJ, R Thornhill 1994 Fluctuating asymmetry and sexual selection. Trends Ecol Evol 9:21-25.

Zakharov V 1987 Animal asymmetry: populations phenogenetic approach. Nauka, Moscow.

Zar JH 1984 Biostatistical analysis. Prentice Hall, Englewood Cliffs, N.J. 